Pesq. Vet. Bras. 29(1):52-58, janeiro 2009

\title{
Microrganismos patogênicos, celularidade e resíduos de antimicrobianos no leite bovino produzido no sistema orgânico'
}

\author{
Márcio Garcia Ribeiro²*, Juliana Santos Geraldo ${ }^{3}$, Hélio Langoni ${ }^{4}$, Gustavo \\ Henrique Batista Lara ${ }^{5}$, Amanda Keller Siqueira ${ }^{5}$, Tatiana Salerno ${ }^{5}$ e Marta \\ Catarina Fernandes ${ }^{5}$
}

\begin{abstract}
Ribeiro M.G., Geraldo J.S., Langoni H., Lara G.H.B., Siqueira A.K., Salerno T. \& Fernandes M.C. 2009. [Pathogenic microorganisms, somatic cell count and drug residues evaluation in organic bovine milk.] Microrganismos patogênicos, celularidade e resíduos de antimicrobianos no leite bovino produzido no sistema orgânico. Pesquisa Veterinária Brasileira 29(1):52-58. Disciplina de Enfermidades Infecciosas dos Animais, Departamento de Higiene Veterinária e Saúde Pública, Faculdade de Medicina Veterinária e Zootecnia, Universidade Estadual Paulista, Botucatu, SP 18618-000, Brazil. E-mail: mgribeiro@fmvz.unesp.br

In last years increase the importance of milk quality and conditions of bovine milking. Simultaneously, increase the interest about organic milk and derivates. The aim of present study was investigate the milk pathogens, sensitivity and multiple drug resistance of isolates, somatic cell count and residues of drugs in milk, from cattle with and without mastitis, come from four little organic dairy farms in State of São Paulo, Brazil. Were used 148 cattle on the middle period of lactation. From these, two showed clinical mastitis, 72 subclinical mastitis and 74 without signs of mammary inflammation (controls). Staphylococcus aureus (25.7\%), Streptococcus spp. (21.4\%), Corynebacterium bovis (12.9\%), Streptococcus agalactiae (4.3\%) and Staphylococcus spp. (4.3\%) were the more-frequent microorganisms isolated from animals with mastitis. Aspergillus spp. was isolated from one animal. Ceftiofur $(95.2 \%)$, oxacillin $(84.2 \%)$, gentamicin $(76.3 \%)$ and cefoperazone $(70.3 \%)$ were the more effective drugs. High resistance of isolates were found to penicillin (53.5\%), ampicillin (41.6\%) and neomycin (38.6\%). Multiple drug resistance to three or more drugs was observed in 40 $(39.6 \%)$ isolates. Media of somatic cell count encountered in animals with mastitis and controls were $175,742.67 \mathrm{cs} / \mathrm{mL}$ and $58,227.6 \mathrm{cs} / \mathrm{mL}$, respectively. Antimicrobials residues in milk were detected in four $(2.7 \%)$ animals. The present findings showed the low somatic cell count of animals, indicative of good quality of milk. However, pointed the need of control measures for contagious pathogens of bovine mastitis and more attention for prohibition of antimicrobial use in organic dairy farms.
\end{abstract}

INDEX TERMS: Organic milk, mastitis, bovine, somatic cell count, residues, multiresistance.

\footnotetext{
${ }^{1}$ Recebido em 22 de abril de 2008.

Aceito para publicação em 5 de agosto de 2008.

2 Disciplina de Enfermidades Infecciosas dos Animais, Departamento de Higiene Veterinária e Saúde Pública, Faculdade de Medicina Veterinária e Zootecnia (FMVZ), Universidade Estadual Paulista "Júlio de Mesquita Filho" (Unesp), Botucatu, SP 18.618-000, Brasil. *Autor para correspondência: mgribeiro@fmvz.unesp.br

${ }^{3}$ Acadêmica do Curso de Medicina Veterinária, Unesp-Botucatu, SP. Bolsista de Iniciação Científica da Fundação de Amparo à Pesquisa do Estado de São Paulo (FAPESP, Projeto 06/57994-4).

4 Disciplina de Zoonoses, Departamento de Higiene Veterinária e Saúde Pública, FMVZ, Unesp-Botucatu, SP.

${ }^{5}$ Pós-graduandos em Saúde Animal, Saúde Pública Veterinária e Segurança Alimentar (SASPVSA), FMVZ, Unesp-Botucatu, SP.
}

RESUMO.- Nos últimos anos cresce a preocupação dos consumidores quanto à qualidade do leite e às condições de produção e bem-estar dos animais. Simultaneamente, aumenta o interesse e o consumo de produtos e subprodutos de origem animal produzidos no sistema orgânico, com destaque para o leite e derivados. O presente estudo investigou a presença de microrganismos patogênicos, a sensibilidade e a multi-resistência dos isolados aos antimicrobianos, a celularidade e a presença de resíduos de drogas no leite de vacas, com e sem mastite, produzido no sistema orgânico. Foram amostradas 148 vacas no período médio de lactação, das quais duas com mastite clínica, 
72 com mastite subclínica e 74 sem mastite (controles), provenientes de quatro pequenas propriedades do interior do Estado de São Paulo, certificadas como orgânicas. Staphylococcus aureus $(25,7 \%)$, Streptococcus spp. $(21,4 \%)$, Corynebacterium bovis (12,9\%), Streptococcus agalactiae $(4,3 \%)$ e Staphylococcus spp. $(4,3 \%)$ foram os microrganismos mais frequentemente isolados nos animais com mastite. Aspergillus spp. foi isolado de um animal. Ceftiofur $(95,2 \%)$, oxacilina $(84,2 \%)$, gentamicina $(76,3 \%)$ e cefoperazona $(70,3 \%)$ foram os antimicrobianos mais efetivos frente aos isolados. As maiores taxas de resistência das linhagens foram constatadas para penicilina $(53,5 \%)$, ampicilina $(41,6 \%)$ e neomicina (38,6\%). Multi-resistência a três ou mais fármacos foi encontrada em 40 (39,6\%) linhagens. A média da contagem de células somáticas das propriedades para animais com mastite foi 175.742,67 céls $/ \mathrm{mL}$, enquanto que para os animais controles foi $58.227,6$ céls $/ \mathrm{mL}$. A presença de resíduos de antimicrobianos foi observada no leite de quatro $(2,7 \%)$ animais. Os resultados revelaram baixa celularidade média nos animais, indicativo de boa qualidade do leite. Entretanto, apontam para a necessidade da adoção de medidas de controle para microrganismos contagiosos e maior rigor na proibição do uso de antimicrobianos em fazendas de leite orgânico.

TERMOS DE INDEXAÇÃO: Leite orgânico, mastite, bovino, contagem de células somáticas, resíduos, multi-resistência.

\section{INTRODUÇÃO}

O leite é o mais nobre dos produtos de origem animal, notadamente pelo elevado valor nutricional para crianças e adultos, bem como seus derivados que, igualmente, se constituem em iguarias de alto valor nutritivo, e fonte de renda para os diferentes segmentos da cadeia produtiva do leite (Ribeiro 2008).

Nas últimas décadas é notória a preocupação com a qualidade e inocuidade dos produtos e subprodutos de origem animal consumidos pela população. Esta tendência mundial fomentou o crescimento significativo, em vários países, das propriedades rurais de produção orgânica, das quais o leite e derivados figuram dentre os principais produtos de interesse comercial (Comerón \& Andreo 2000).

O termo orgânico refere-se a alimentos de origem animal e vegetal produzidos sem o uso de fertilizantes, pesticidas, inseticidas, antimicrobianos, anti-parasitários, transgênicos, ou qualquer outra droga que possua resíduos nocivos à saúde humana, incluindo produtos de uso agropecuário destinados à animais de exploração leiteira. As propriedades de produção orgânica são credenciadas por órgãos competentes e se caracterizam pela otimização de recursos naturais e sócio-econômicos, respeitando a integridade cultural do homem do campo, adotando práticas de manejo que minimizem danos à natureza e preservem o bem-estar animal visando, em suma, a exploração do ambiente e dos animais de forma ecológica, racional e sustentável (Instituto Biodinâmico 2000). Conceitualmente, as propriedades orgânicas devem ge- rar alimentos de alta qualidade nutricional, isentos de resíduos de produtos químicos nocivos ao homem (Comerón \& Andreo 2000). Com efeito, o valor agregado do produto orgânico é duas ou três vezes superior ao leite e subprodutos produzidos sob a forma convencional, fato que tem motivado a migração de produtores tradicionais para a modalidade orgânica, vislumbrados com a possibilidade de produção de leite e derivados de alto valor, sem a necessidade de investimentos de vulto.

Estima-se que o mercado mundial de produtos orgânicos tenha atingido aproximadamente US $\$ 25$ milhões em 2001. Somente nos EUA, a procura por produtos orgânicos revela aumento de $20 \%$ ao ano (Penteado 2000). Entretanto, a produção de leite orgânico no Brasil pode ser considerada insipiente. Em que pese o alto potencial nacional para a produção de alimentos orgânicos, estimase que o Brasil produza ao redor de seis milhões de litros de leite orgânico/ano, notadamente insuficiente para atender a demanda atual ao redor de 600 milhões de litros/ ano (Arve 1999). Em todo o Estado de São Paulo, aproximadamente duas dezenas de propriedades rurais estão devidamente certificadas e atendem às exigências de produção de leite e derivados orgânicos (Instituto Biodinâmico 2000).

Em 1999 foi sancionada a Instrução Normativa 07 (IN 007) pelo Ministério da Agricultura, Pecuária e Abastecimento (MAPA), com fim precípuo de regulamentar a produção de leite orgânico no Brasil, assegurar a qualidade do produto, garantir competitividade de mercado para os produtos de origem animal e vegetal, bem como nortear as exigências para o credenciamento das propriedades $e$ Instituições certificadoras (Brasil 1999). No mesmo contexto, foi sancionada pelo MAPA em 2002 a Instrução Normativa 051 (IN 051) (Brasil 2002), que promoveu várias modificações quanto às exigências da produção de leite em animais domésticos, com vistas a melhorar e assegurar as condições nutricionais e de inocuidade do produto e derivados, procurando adequar gradativamente a produção nacional, com base na qualidade e demandas de mercado. Dentre as principais modificações e/ou aumento no rigor de fiscalização, assumem destaque as exigências quanto aos valores de células somáticas, contagem bacteriana total, ausência de resíduos de antimicrobianos, bem como a colheita a granel nos tanques de expansão, praticamente banindo o uso de latões. Apesar da regulamentação dos métodos e prerrogativas para a produção do leite orgânico no Brasil pela IN 007, são escassos os estudos no país voltados à avaliação da qualidade do leite orgânico (Campos 2004). Paralelamente, muitos parâmetros de qualidade do produto estão apoiados na IN 051. Esta interface é salutar, embora vários métodos de criação e manejo dos animais mantidos no sistema convencional e orgânico sejam distintos, o que reforça a necessidade de estudos específicos dos parâmetros de qualidade do leite e derivados orgânicos.

Em diversos países, as condições de qualidade microbiológica e físico-química, assim como a presença de 
resíduos de antimicrobianos e pesticidas no leite bovino produzido no sistema orgânico tem sido motivo de estudos (Kristensen \& Kristensen 1998, Ginot-Thomas et al. 1991). No Brasil, diferentes autores têm se preocupado em determinar parâmetros de qualidade no leite convencional (Nader Filho \& Rossi Júnior 1989, Nader Filho et al. 1997, Nascimento et al. 2001, Cordeiro et al. 2002). No entanto, as pesquisas com leite orgânico ainda são escassas no país (Campos, 2004).

O presente estudo investigou a ocorrência de microrganismos patogênicos, a resistência múltipla dos isolados aos antimicrobianos, a celularidade e a presença de resíduos de antimicrobianos no leite produzido no sistema orgânico em propriedades do interior do Estado de São Paulo.

\section{MATERIAL E MÉTODOS}

\section{Propriedades}

O estudo foi conduzido ao longo de um ano em quatro pequenas propriedades rurais localizadas no interior do Estado de São Paulo certificadas como orgânicas que utilizam mãode-obra essencialmente familiar. Todas as propriedades possuíam entre 10 a 40 animais em lactação, de raça predominantemente girolanda, em regime de uma ordenha diária, manual ou mecânica (balde ao pé).

\section{Animais e diagnóstico de mastite}

Foram utilizadas 74 vacas com mastite (clínica ou subclínica) e 74 vacas sem mastite (controle) (Quadro 1), totalizando 148 animais. As amostras de leite dos animais com e sem mastite foram colhidas no período médio de lactação. A amostragem obtida dos animais controle foi colhida ao acaso. O diagnóstico da mastite clínica foi fundamentado nas alterações macroscópicas do leite (presença de pus, dessora, grumos e/ou estrias de sangue) na prova da caneca telada de fundo escuro e na presença de sinais de inflamação na glândula mamária. A mastite subclínica foi diagnosticada utilizando o teste clássico de California Mastitis Test (CMT) (Schalm et al. 1971). O leite de tetos com escore 2+ ou 3+ no CMT foi utilizado para isolamento microbiano.

\section{Isolamento e caracterização dos microrganismos}

As amostras de leite foram colhidas após anti-sepsia dos tetos com solução de iodo glicerinado a $1 \%$, transportadas sob temperatura de refrigeração $\left(4-8^{\circ} \mathrm{C}\right)$ para o cultivo microbiano. Todas as amostras foram semeadas nos meios de ágar san-

Quadro 1. Fêmeas bovinas com e sem mastite de quatro propriedades rurais de produção orgânica no interior do Estado de São Paulo, amostradas para o diagnóstico microbiológico de mastite, celularidade e resíduos de antimicrobianos, 2007

\begin{tabular}{ccccc}
\hline Propriedade & $\begin{array}{c}\text { № de ani- } \\
\text { mais com } \\
\text { mastite } \\
\text { clínica }\end{array}$ & $\begin{array}{c}\text { № de ani- } \\
\text { mais com } \\
\text { mastite } \\
\text { subclínica }\end{array}$ & $\begin{array}{c}\text { № de animais } \\
\text { controle }\end{array}$ & $\begin{array}{c}\text { № de animais } \\
\text { amostrados } \\
\text { por pro- } \\
\text { priedade }\end{array}$ \\
\hline A & 01 & 08 & 18 & 27 \\
B & - & 25 & 13 & 38 \\
C & - & 03 & 12 & 15 \\
D & 01 & 36 & 31 & 68 \\
Total & 02 & 72 & 74 & 148
\end{tabular}

gue bovino desfibrinado (5\%) e ágar MacConkey, mantidas a $37^{\circ} \mathrm{C}$, em aerobiose, por 72 horas. Simultaneamente, as amostras foram semeadas em ágar Sabouraud, mantidas a $25^{\circ} \mathrm{e}$ $37^{\circ} \mathrm{C}$, por 14 dias. As linhagens de microrganismos de origem bacteriana e fúngica foram identificadas segundo as características morfo-tintoriais, bioquímicas e de cultivo (Krieg \& Holt 1994, Quinn et al. 1994, Lacaz et al. 1998).

\section{Perfil de sensibilidade microbiana}

As linhagens de microrganismos isoladas foram submetidas à prova de sensibilidade microbiana pelo método de difusão com discos (CLSI/NCCLS 2003), utilizando os principais antimicrobianos disponíveis comercialmente e indicados para a terapia intramamária e/ou parenteral de mastite bovina (Ribeiro 2008), a saber: ampicilina (10 mcg), cefoperazona sódica (75 mcg), ceftiofur (30 mcg), enrofloxacina ( $5 \mathrm{mcg})$, gentamicina (10 mcg), neomicina (30 mcg), oxacilina $(5 \mathrm{mcg})$ e penicilina (10UI). A ocorrência de multi-resistência foi considerada nas linhagens que apresentaram resistência simultânea a três ou mais antimicrobianos.

\section{Determinação de Escherichia coli enterohemorrágica sorotipo 0157:H7}

Simultaneamente ao diagnóstico microbiológico nos meios convencionais, foi realizada a semeadura do leite no ágar MacConkey Sorbitol, utilizado para o diagnóstico de estirpes do sorotipo O157:H7 de E. coli. O meio foi mantido a temperatura de $37^{\circ} \mathrm{C}$, em aerobiose, por 48 horas, para identificação de estirpes não fermentadoras de sorbitol (Vernozy-Rozand 1997). Como controle de E. coli O157:H7 foi utilizada cepa EDL 933, cedida pelo Instituto de Ciências Biomédicas da Universidade de São Paulo.

\section{Contagem eletrônica de células somáticas}

Todas as amostras de leite dos animais com e sem mastite foram colhidas em tubo apropriado de plástico, homogeneizadas com conservante celular de leite (bronopol) e dispostas em caixas apropriadas em temperatura ambiente, visando a contagem eletrônica de células somáticas em no máximo cinco dias, de acordo com as recomendações técnicas do equipamento (Somacount 300$)^{6}$. No Brasil ainda não existem parâmetros de qualidade específicos para o leite produzido no sistema orgânico. Assim, foi utilizado como parâmetro de celularidade no presente estudo, o valor de $750.000 \mathrm{céls} / \mathrm{mL}$ indicado pela Instrução Normativa 051 (Brasil, 2002).

\section{Avaliação de resíduos de antimicrobianos no leite}

A detecção de resíduos foi realizada no leite procedente de todos os animais utilizando-se kit comercial, conforme as recomendações do fabricante ${ }^{7}$, indicado para o diagnóstico dos principais grupamentos de antimicrobianos disponíveis em medicina veterinária. As amostras foram colhidas e acondicionadas em frascos esterilizados e congeladas $\left(-20^{\circ} \mathrm{C}\right)$ até $\mathrm{O}$ processamento. A detecção de resíduos por este método utiliza ampolas de meio de cultura contendo o Bacillus stearothermophilus var. calidolactis. São adicionados $0,1 \mathrm{~mL}$ da amostra de leite no receptáculo do kit contendo o microrganismo e indicador de $\mathrm{pH}$, e mantidos em temperatura de $64^{\circ} \mathrm{C}+/-0,5$,

\footnotetext{
${ }^{6}$ Somacount 300, Bentley, USA.

7 Delvotest тм: DSM Food Specialties Dairy Ingredients, The Netherlands.
} 
durante 3,0 horas, em banho-maria. Na ausência de resíduos de antimicrobianos ocorre a multiplicação bacteriana, produção de ácido e alteração da cor original do indicador (de púrpura para amarelo). Na presença de resíduos de antimicrobianos a multiplicação bacteriana é retardada ou inibida, ocorrendo inibição ou acidificação pobre do meio (tonalidade púrpura a azulada).

\section{RESULTADOS E DISCUSSÃO}

Os principais microrganismos isolados nos animais com mastite foram Staphylococcus aureus $(25,7 \%)$, Streptococcus spp. (21,4\%), Corynebacterium bovis $(12,9 \%)$, Streptococcus agalactiae (4,3\%) e Staphylococcus spp. $(4,3 \%)$, em cultura pura ou em associação (Quadro 2 ). Esses achados são condizentes com a literatura visto que estes microrganismos são reconhecidos como os principais agentes causais de mastite em bovinos (Langoni et al. 1998a, Costa 2001, Santos \& Fonseca 2007), incluindo animais manejados no sistema orgânico (GuinotThomas et al. 1991, Roesch et al. 2007).

A mastite é reconhecida como a principal doença que afeta animais de produção direcionados à exploração leiteira, decorrente das alterações provocadas na composição físico-química e na celularidade do leite, dos prejuízos com a redução na produção determinados pelos agravos no tecido glandular, somados aos reflexos na Saúde Pública (Langoni 2000, Ribeiro 2008). Convencionalmente, os microrganismos envolvidos na casuística da mastite estão agrupados em contagiosos e ambientais, com base nas fontes de infecção e vias de transmissão (Langoni et al. 1998a). No Brasil e em outros países, a maior freqüência de mastite em animais de produção está intimamente relacionada aos microrganismos contagiosos, representados principalmente pelos gêneros Staphylococcus (S. aureus), Streptococcus

Quadro 2. Freqüência de microrganismos isolados em cultura pura ou em associação, em 148 fêmeas bovinas com e sem mastite, criadas em sistema orgânico de produção em quatro propriedades rurais do interior do Estado de São Paulo, 2007

\begin{tabular}{|c|c|c|c|c|}
\hline \multirow[t]{2}{*}{ Microrganismos } & \multicolumn{2}{|c|}{ Animais com mastite } & \multicolumn{2}{|c|}{ Controle } \\
\hline & $\begin{array}{c}\text { Freqüên- } \\
\text { cia ab- } \\
\text { soluta }\end{array}$ & $\begin{array}{l}\text { Freqüên- } \\
\text { cia rela- } \\
\text { tiva (\%) }\end{array}$ & $\begin{array}{c}\text { Freqüên- } \\
\text { cia ab- } \\
\text { soluta }\end{array}$ & $\begin{array}{l}\text { Freqüên- } \\
\text { cia rela- } \\
\text { tiva (\%) }\end{array}$ \\
\hline Staphylococcus aureus & 18 & 25,7 & 10 & 27,8 \\
\hline Streptococcus spp. & 15 & 21,4 & 09 & 25,0 \\
\hline Corynebacterium bovis & 09 & 12,9 & 09 & 25,0 \\
\hline Staphylococcus spp. & 03 & 4,3 & 03 & 8,3 \\
\hline Streptococcus agalactiae & 03 & 4,3 & - & - \\
\hline Alcaligenes faecalis & 02 & 2,9 & - & - \\
\hline Enterobacter aerogenes & 01 & 1,4 & - & - \\
\hline S. aureus + Streptococcus spp. & 15 & 21,4 & 02 & 5,5 \\
\hline S. aureus + C. bovis & 02 & 2,9 & 02 & 5,5 \\
\hline $\begin{array}{l}\text { S. aureus + Streptococcus spp. } \\
+ \text { Aspergillus spp. }\end{array}$ & 01 & 1,4 & - & - \\
\hline $\begin{array}{l}\text { S. aureus + Streptococcus spp. } \\
+ \text { C. bovis }\end{array}$ & 01 & 1,4 & - & - \\
\hline $\begin{array}{l}\text { Streptococcus spp. } \\
+ \text { Staphylococcus spp. }\end{array}$ & - & - & 01 & 2,8 \\
\hline
\end{tabular}

(S. agalactiae) e Corynebacterium bovis (C. bovis). Dentre os ambientais, assumem importância na gênese da mastite as enterobactérias (Escherichia coli, Klebsiella pneumoniae e Enterobacter aerogenes), Nocardia spp., Pseudomonas aeruginosa, algas (Prototheca zopfii), fungos e leveduras (Langoni et al. 1998a,b, Andrade et al. 2001, Ribeiro 2008).

Ao longo do estudo foram diagnosticados dois animais com mastite clínica e 72 com mastite subclínica. De maneira similar aos achados do presente estudo, a maior prevalência de mastite subclínica, comparativamente a clínica, em rebanhos bovinos com produção de leite orgânico também tem sido assinalada em outros países, causada predominantemente por microrganismos de origem contagiosa (Guinot-Thomas et al. 1991, Roesch et al. 2007). Este achado pressupõe que devem ser direcionados esforços no controle da mastite nas quatro propriedades estudadas, priorizando medidas voltadas aos microrganismos contagiosos, que possam ser adequadas à sistemática orgânica de produção, incluindo noções de higiene do ordenhador, manejo adequado na ordenha, adoção de pós-dipping e descarte de animais com mastite crônica.

Nos 74 animais controles foram isolados, predominantemente, os mesmos grupos de microrganismos identificados nos animais com mastite, embora em menor freqüência (Quadro 2). Este achado provavelmente possa ser creditado à presença destes grupos de microrganismos na microbiota da pele do úbere e da cisterna do teto em fêmeas bovinas sadias e à dependência de determinados fatores predisponentes, intimamente relacionados às deficiências na higiene de ordenha, que podem estabelecer a infecção mamária, via ascendente pelo canal do teto (Radostits et al. 2007). Ademais, reforça a condição que muitos animais do rebanho permanecem em estado de portador de microrganismos, notadamente do grupo dos contagiosos, dificultando as ações de controle no rebanho, visto que estes animais não exteriorizam sinais clínicos de mastite, tampouco acusam reações no CMT (Santos \& Fonseca 2007).

Em somente um animal foi isolado Aspergillus spp. O resultado do presente estudo encontra respaldo em estudos similares que também apontaram para a baixa ocorrência de mastite bovina por fungos e leveduras (Langoni et al. 1998b, Lacaz et al. 1998).

Nenhuma amostra de leite acusou o isolamento de $E$. coli no ágar MacConkey e ágar MacConkey Sorbitol. Ribeiro et al. (2006), no Brasil, estudaram recentemente os principais fatores de virulência em 120 linhagens de $E$. coli isoladas de casos de mastite clínica e subclínica em vacas criadas no sistema convencional, e também não obtiveram êxito na identificação do sorotipo O157:H7. Apesar da relevância deste sorotipo patogênico de E. coli em outros países (Sussman 1997, Radostits et al. 2007), permanece incerta a sua participação no Brasil como agente primário de mastite.

Ceftiofur $(95,2 \%)$, oxacilina $(84,2 \%)$, gentamicina $(76,3 \%)$ e cefoperazona $(70,3 \%)$ foram os antimicrobia- 


\section{Quadro 3. Perfil in vitro de sensibilidade microbiana em linhagens de microrganismos isolados de vacas com e sem mastite, provenientes de quatro propriedades orgânicas do interior do Estado de São Paulo, 2007}

\begin{tabular}{|c|c|c|c|}
\hline \multirow[t]{2}{*}{ Antimicrobianos } & Sensível & $\begin{array}{c}\text { Parcialmente } \\
\text { Sensível }\end{array}$ & Resistente \\
\hline & $\begin{array}{c}\text { № de micror- } \\
\text { ganismos/№ } \\
\text { total tes- } \\
\text { tado (\%) }\end{array}$ & $\begin{array}{c}\text { № de micror- } \\
\text { ganismos/№ } \\
\text { total tes- } \\
\text { tado (\%) }\end{array}$ & $\begin{array}{c}\text { № de micror- } \\
\text { ganismos/№ } \\
\text { total tes- } \\
\text { tado (\%) }\end{array}$ \\
\hline & $57 / 101(56,5)$ & 2/101 $(1,9)$ & $42 / 101(41,6)$ \\
\hline Cefoperazona (75mcg) & $71 / 101$ & $19 / 101(18,8)$ & $11 / 101(10,9)$ \\
\hline Ceftiofur (30mcg) & 96/101 (95,2) & $1 / 101(0,9)$ & $4 / 101(3,9)$ \\
\hline Enrofloxacina (5mcg) & $57 / 101(56,5)$ & $23 / 101(22,7)$ & $21 / 101(20,8)$ \\
\hline Gentamicina (10mcg) & $77 / 101(76,3)$ & $4 / 101(3,9)$ & 20/101 $(19,8)$ \\
\hline Neomicina $(30 \mathrm{mcg})$ & $44 / 101(43,6)$ & $18 / 101(17,8)$ & $39 / 101(38,6)$ \\
\hline Oxacilina (5mcg) & $85 / 101(84,2)$ & $1 / 101(0,9)$ & $15 / 101(14,9)$ \\
\hline Penicilina (10 UI) & $29 / 101(28,7)$ & $18 / 101(17,8)$ & $54 / 101(53,5)$ \\
\hline
\end{tabular}

nos mais efetivos frente aos isolados (Quadro 3), que se constituem em drogas predominantemente derivadas dos beta-lactâmicos. De maneira similar, Tikofsky et al. (2003) também encontraram alta sensibilidade de linhagens de microrganismos isolados de vacas com mastite criadas em sistema orgânico, especialmente para os derivados beta-lactâmicos. No entanto, a limitação do uso de antimicrobianos em fêmeas bovinas com mastite criadas no sistema orgânico de produção dificulta a interpretação dos achados do presente estudo sob o ponto de vista terapêutico. A resistência múltipla dos microrganismos pode ser creditada ao fato de que as propriedades estudadas foram recentemente moduladas de convencionais para orgânicas, mantendo, provavelmente, as mazelas do uso indevido de antimicrobianos na terapia da mastite.

O reconhecimento do perfil de sensibilidade microbiana é fundamental para avaliar a ocorrência de linhagens multiresistentes. Penicilina $(53,5 \%)$, ampicilina $(41,6 \%)$ e neomicina $(38,6 \%)$ foram os antimicrobianos que apresentaram as maiores taxas de resistência frente aos isolados (Quadro 3). A presença de linhagens resistentes a três ou mais antimicrobianos foi observada em 40 (39,6\%) dentre 101 isolados. Em contraste, Bennedsgaard et al. (2006) na Dinamarca, encontraram baixo percentual de resistência de linhagens de microrganismos isolados de fêmeas bovinas criadas no sistema orgânico frente à penicilina, e atribuíram tal achado a menor pressão seletiva dos microrganismos multi-resistentes, especialmente os produtores de beta-lactamases, pelo uso proibitivo dos antimicrobianos no sistema orgânico de produção no país.

As quatro propriedades com sistema orgânico de produção revelaram valores médios de celularidade abaixo de 500.000 células somáticas $/ \mathrm{mL}$, que seriam indicativos de boa qualidade do produto, apesar das diferenças notórias e esperadas entre os animais com mastite e controles (Quadro 4). Somente a propriedade (C) apresentou valores de média de celularidade em animais com mastite acima de $1.000 .000 \mathrm{cs} / \mathrm{mL}$, considerado em desacordo com a atual IN 51.

A infecção mamária em animais de produção induz ao aumento significativo do número de células somáticas. A contagem eletrônica de células é utilizada atualmente no monitoramento da saúde dos rebanhos leiteiros, assim como para o pagamento por qualidade do leite. A IN 51 permite que o leite entregue nos laticínios contenha até $750.000 \mathrm{cs} / \mathrm{mL}$, com o compromisso de reduzir gradualmente tal patamar, com vistas a melhorar a qualidade do leite produzido no país (Brasil 2002).

A baixa celularidade dos rebanhos estudados pode refletir a preocupação dos produtores do leite orgânico com o manejo mais harmonioso e saudável dos animais, que resultaria em rebanhos com bom controle de mastite. $\mathrm{Na}$ Suécia, Hamilton et al. (2006) também relataram baixas contagens de células somáticas ( 83 a $280 \times 10^{3}$ células $/ \mathrm{mL}$ ) e predominância de mastite contagiosa em 26 rebanhos orgânicos, comparativamente a rebanhos convencionais no mesmo país. No entanto, somente a baixa celularidade não é suficiente para assegurar a boa qualidade do leite orgânico. $\mathrm{O}$ isolamento de patógenos como $S$. aureus, tanto em animais com mastite como nos controles nas propriedades estudadas, reforça a necessidade da adoção de medidas de profilaxia e controle de mastite e boas práticas para obtenção de ordenha higiênica. Contrariamente, no interior do Estado de São Paulo, Campos (2004) descreveu altas contagens celulares em vacas submetidas à produção de leite orgânico, embora não tenha identificado qualitativamente as espécies de microrganismos presentes no leite destes animais.

A presença de resíduos de antimicrobianos foi evidenciada em quatro $(2,7 \%)$ animais amostrados no presente estudo, provenientes de duas propriedades diferentes.

\section{Quadro 4. Contagem de células somáticas em vacas com e sem mastite em quatro propriedades manejadas no sistema orgânico de produção no interior do Estado de São Paulo, 2007}

\begin{tabular}{cccc}
\hline Propriedades & $\begin{array}{c}\text { Média dos animais } \\
\text { com mastite } \\
\left(\mathrm{CCS}^{*} / \mathrm{n}^{\circ} \text { de animais }\right)\end{array}$ & $\begin{array}{c}\text { Média dos animais } \\
\text { sem mastite } \\
\left(\mathrm{CCS}^{*} / \mathrm{n}^{\circ} \text { de animais }\right)\end{array}$ & $\begin{array}{c}\text { Média geral / propriedade } \\
\left(\mathrm{CCS}^{*} / \mathrm{n}^{\circ} \text { total de animais }\right)\end{array}$ \\
\hline $\mathrm{A}$ & $351.666,7(3.165 .000 / 9)$ & $65.000,0(1.170 .000 / 18)$ & $160.555,5(4.335 .000 / 27)$ \\
$\mathrm{B}$ & $80.320,0(2.008 .000 / 25)$ & $3.769,2(49.000 / 13)$ & $54.131,6(2.057 .000 / 38)$ \\
$\mathrm{C}$ & $1.514 .333,3(4.543 .000 / 3)$ & $152.166,0(1.826 .000 / 12)$ & $424.600,0(6.369 .000 / 15)$ \\
D & $88.890,7(3.288 .958,3 / 37)$ & $40.769,2(1.263 .846,1 / 31)$ & $66.953,0(4.552 .804,4 / 68)$ \\
Média geral & $175.742,67(13.004 .958,0 / 74)$ & $58.227,6(4.308 .846,1 / 74)$ & $116.985,2(17.313 .804 / 148)$
\end{tabular}

\footnotetext{
* $\mathrm{CCS}=$ contagem de células somáticas $/ \mathrm{mL}$.
} 
Este resultado está em desacordo com as normas da IN 007 e IN 051 do MAPA (Brasil 1999, 2002) que proibem a presença de qualquer resíduo de antimicrobiano, sob pena de descarte imediato do produto e conseqüente prejuízo ao produtor. Ademais, este resultado é altamente preocupante no contexto de Saúde Pública, em face dos riscos do consumo de leite e derivados pelo homem contendo resíduos de antimicrobianos, que pode levar a graves manifestações de hipersensibilidade e outras afecções orgânicas (Andrade et al. 2001).

Diferentes estudos conduzidos em outros países têm investigado a persistência de resíduos de antimicrobianos após a terapia intramamária de vacas em regime convencional de ordenha, visando determinar os períodos de carência dos medicamentos (Egan \& Meaney 1985, Seymour \& Jones 1988). No Brasil, Raia et al. (1999) avaliaram a permanência de resíduos de antimicrobianos em vacas tratadas por via sistêmica com penicilina e dihidroestreptomicina e observaram que $100 \%$ dos animais apresentaram resíduos no leite com $48 \mathrm{~h}, 93,3 \%$ com $72 \mathrm{~h}$ e $66,7 \%$ com $96 \mathrm{~h}$, respectivamente. Em contraste, são escassos os estudos na literatura nacional direcionados à determinação de resíduos de antimicrobianos em leite produzido no sistema orgânico. Em animais criados no sistema de produção orgânica acometidos por infecções graves, e que necessitem do uso de alopatia, recomenda-se que o leite não seja utilizado por um período duas vezes maior do que o permitido na produção convencional, minimizando assim, o risco de resíduos no produto (Instituto Biodinâmico 2000, Penteado 2000). Animais com doenças crônicas, recidivantes, e que necessitem de uso regular de alopatia devem ser descartados do sistema orgânico de produção.

\section{CONCLUSÕES}

Os resultados do presente estudo apontaram para a baixa celularidade dos rebanhos indicando boa qualidade do produto, apesar da alta ocorrência de mastite contagiosa.

Estes achados indicam a necessidade de adequação das práticas voltadas à ordenha higiênica, especialmente direcionada aos microrganismos contagiosos, com vistas a assegurar melhor qualidade do leite comercializado, ou mesmo da matéria prima utilizada na elaboração de derivados lácteos por estas propriedades.

A presença de resíduos de antimicrobianos é fator preocupante e depreciativo do produto, decorrente dos prejuízos ao produtor com o descarte do leite, somados aos reflexos na Saúde Pública e deve ser motivo de esforços dos produtores de leite orgânico no sentido de evitar a presença de qualquer tipo de resíduo nocivo que possa gerar agravos à saúde humana.

Agradecimentos.- À Fundação de Amparo à Pesquisa do Estado de São Paulo (FAPESP) pela concessão de Bolsa de Iniciação Científica (Projeto 06/57994-4). A Global Food Sistemas, Ingredientes e Tecnologia para Alimentos Ltda., São Paulo, SP, pela doação do Kit de avaliação de resíduos de antimicrobianos.

\section{REFERÊNCIAS}

Andrade S.F., Giuffrida R. \& Ribeiro M.G. 2001. Quimioterápicos, Antimicrobianos e Antibióticos, p.13-58. In: Andrade S.F. (Ed.), Manual de Terapêutica Veterinária. Roca, São Paulo, SP.

Arve A.M. 1999. Organic ways in Denmark. Scandinavian Dairy Information 4:12-15.

Bennedsgaard T.W., Thamsborg S.M., Aarestrup F.M., Enevoldsen C., Vaarst M. \& Christoffersen A.B. 2006. Resistance to penicillin of Staphylococcus aureus from cows with high somatic cell counts in organic and conventional dairy herds in Denmark. Acta Vet. Scand. 48:1-6.

Brasil 1999. Ministério da Agricultura, Pecuária e Abastecimento. Instrução Normativa 007 de 17 de maio de 1999. Normas Disciplinadoras para a Produção, Tipificação, Processamento, Envase, Distribuição, Identificação e Certificação de Qualidade de Produtos Orgânicos, sejam de Origem Animal ou Vegetal. Brasília, DF. Disponível em: (http://www.agricultura.gov.br/. Agricultura orgânica. Produtos orgânicos). Acesso em 9 de março de 2006.

Brasil 2002. Ministério da Agricultura, Pecuária e Abastecimento. Instrução Normativa 051. Regulamentos Técnicos de Produção, Identidade e Qualidade do Leite tipo A, do Leite tipo B, do Leite tipo C, do Leite Pasteurizado e do Leite Cru Refrigerado e o Regulamento Técnico da Coleta de Leite Cru Refrigerado e seu Transporte a Granel. Brasília, DF.

Campos E.P.C. 2004. Qualidade microbiológica, físico-química e pesquisa de resíduos de antibióticos e pesticidas no leite bovino produzido pelo sistema convencional e pelo sistema orgânico. Tese de Mestrado, Faculdade de Medicina Veterinária e Zootecnia, Universidade Estadual Paulista (Unesp), Botucatu, SP. 58p.

CLSI/NCCLS 2003. Padronização dos testes de sensibilidade aos antimicrobianos por disco-difusão. $8^{a}$ ed. Disponível em: <http:// sbmicrobiologia.org.br/clsi_OPASM2-A8.pdf>, Acesso em 26 set. 2007.

Comerón E.A. \& Andreo N.A. 2000. Produção, industrialização e comercialização do leite orgânico na Argentina. Anais 2 Simpósio sobre Sustentabilidade da Pecuária Leiteira no Brasil, Goiânia. Embrapa Gado de Leite, Juiz de Fora.

Cordeiro C.A.M., Almeida C.L. \& Martins M.L. 2002. Qualidade microbiológica do leite pasteurizado tipo C proveniente de micro-usinas de Campos dos Goytacazes, RJ. Higiene Alimentar 16:41-44.

Costa E.O. 2001. Uso de antimicrobianos na mastite, p.443-445. In: Spinosa H.S., Gorniak S.L. \& Bernardi M. (Ed.), Farmacologia Aplicada à Medicina Veterinária. Guanabara Koogan, Rio de Janeiro.

Egan J. \& Meaney W.J. 1985. Persistence of detectable residues of penicillin and cloxacilin in normal and mastitis quarters following intramammmary infusion. Vet. Rec. 116:436-438.

Guinot-Thomas P., Jondreville C. \& Laurent F. 1991. Comparison of milk from farms with biological, conventional and transitional feeding. Milchwissenschaft 46:779-782.

Hamilton C., Emanuelson U., Forslund K., Hansson I. \& Ekman T. 2006. Mastitis and related management factors in certified organic dairy herds in Sweden. Acta Vet. Scand. 48:1-7

Instituto Biodinâmico 2000. Diretrizes. 10ª ed. IBD, Botucatu, SP. 72p. Krieg N.R. \& Holt J.C. 1994. Bergey‘s Manual of Sistematic Bacteriology. 9th ed. Williams and Wilkins, Baltimore. 984p.

Kristensen T. \& Kristensen E.S. 1998. Analysis and simulation molling of the production in Danish organic and conventional dairy herds. Livestock Prod. Sci. 54:55-65.

Lacaz C.S., Porto E., Heins-Vaccari E.M. \& Melo N.T. 1998. Guia para identificação de Fungos, Actinomicetos e Algas de Interesse Médico. Sarvier, São Paulo. 445p.

Langoni H., Silva A.V., Cabral K.G. \& Domingues P.F. 1998a. Aspectos etiológicos na mastite bovina: Flora bacteriana aeróbica. Revta Bras. Med. Vet. 20:204-210. 
Langoni H., Domingues P.F., Chi K.D., Pardo R.B., Cabral K.G. \& Rosa C. 1998b. Participação de leveduras, algas e fungos na mastite bovina. Revta Vet. Zootec. 10:89-98.

Langoni H. 2000. Tendências de modernização do setor lácteo: Monitoramento da qualidade do leite pela contagem de células somáticas. Revta Educ. Cont. CRMV-SP 3:57-64.

Nader Filho A. \& Rossi Júnior O.D. 1989. Avaliação das características microbiológicas do leite tipo $\mathrm{C}$ e das embalagens plásticas utilizadas no envase em uma usina de beneficiamento do Estado de São Paulo, Brasil. Revta Microbiol., São Paulo, 20:261-266.

Nader Filho A., Amaral J.A., Rossi Júnior O.D. \& Schocken D.L. 1997. Características microbiológicas do leite pasteurizado tipo "integral", processado por algumas mini e micro-usinas de beneficiamento do Estado de São Paulo. Higiene Alimentar 11:21-23.

Nascimento G.G.F., Maestro V. \& Campos M.S.P. 2001. Ocorrência de resíduos de antibióticos no leite comercializado em Piracicaba, São Paulo, Brasil. Revta Nutrição 14:119-124.

Penteado S.R. 2000. Introdução à agricultura orgânica. Grafimagem, Campinas. 110p.

Quinn P.J., Carter M.E., Markey B. \& Carter G.R. 1994. Clinical Veterinary Microbiology. Wolfe, London. 648p.

Radostits O.M., Gay C.C., Hinchcliff K.W. \& Constable P.D. 2007. Veterinary Medicine: A textbook of the disease of cattle, horses, sheep, pigs and goats. 10th ed. Saunders Elsevier, USA. 2156p.

Raia R.B., Costa E.O., Garino Júnior F., Watanabe E.T., Thiers F.O. \& Groff M.R. 1999. Estudo da persistência de eliminação de resíduos de antibióticos no leite após o tratamento sistêmico e intramamário de mastite. Revta Núcleo Apoio Pesq. Glândula Mamária e Produção Leiteira 3:4-8.

Ribeiro M.G., Costa E.O., Leite D.S., Langoni H., Garino Júnior F., Victoria C. \& Listoni F.J.P. 2006. Fatores de virulência em linhagens de Escherichia coli isoladas de mastite bovina. Arq. Bras. Med. Vet. Zootec. 58:724-731.

Ribeiro M.G. 2008. Princípios terapêuticos na mastite em animais de produção e de companhia. In: Andrade S.F. (Ed.), Manual de Terapêutica Veterinária. $3^{\underline{a}}$ ed. Roca, São Paulo. 936p.

Roesch M., Doherr G., Schären W., Schällibaum M. \& Blum J.W. 2007. Subclinical mastitis in dairy cows in Swiss organic and conventional production systems. J. Dairy Res. 74:86-92.

Santos M.V. \& Fonseca L.F.L. 2007. Estratégias para o controle de mastite e melhoria da qualidade do leite. Manole, São Paulo. 314p.

Schalm O.W., Carrol E. \& Jain N.C. 1971. Bovine Mastitis. Lea and Febiger, Philadelphia. 360p.

Seymour E.H. \& Jones G.M. 1988. Cowside antibiotic residue testing. J. Dairy Sci. 71:1691-1699.

Sussman M. 1997. Escherichia coli: Mechanisms of virulence. Cambridge University Press, UK. 639p.

Tikofsky L.L., Barlow J.W., Santisteban C. \& Schukken Y.H. 2003. A comparison of antimicrobial susceptibility patterns for Staphylococcus aureus in organic and conventional dairy herds. Microbiol. Drug Resistance 9(1):39-45.

Vernozy-Rozand C. 1997. Detection of Escherichia coli O157:H7 and other verocytotoxin-producing E. coli (VTEC) in food. J. Appl. Microbiol. 82:537-551. 